\title{
Impactos do Parlamento Jovem Brasileiro na motivação e participação política partidária dos egressos
}

\author{
Impacts of Young Brazilian Parliament motivation and partisan \\ political participation of former participants
}

\section{Antonio Teixeira de Barros Lúcio Meireles Martins}

\section{Resumo}

$\mathrm{O}$ artigo analisa os impactos do Parlamento Jovem Brasileiro (PJB) na participação política institucional dos seus egressos. A análise está baseada em levantamento do tipo survey, com questionário aplicado em 2014 aos egressos do PJB, das ediçóes de 2006 a 2013, totalizando 27,48\% deste universo. As conclusóes indicam relevante percentual de jovens motivados e participantes na política partidária, o que representa forte contraste com dados de pesquisas com a juventude em geral. Entre os egressos do sexo masculino, há maior motivação e interesse pela política partidária. A principal conclusão é de que, ao promover o letramento político, amplia-se a confiança nas instituições políticas e estimula-se o engajamento partidário, alterando o processo de desencantamento e desinstitucionalização da ação política.

\section{Palavras-chave}

Juventude; Participação Política; Parlamento Jovem Brasileiro; Partidos Políticos; Câmara dos Deputados.

\section{Abstract}

This paper analyzes the impact of the Young Brazilian Parliament (PJB) in the institutional political participation of former members. The analysis is based on a survey conducted in 2014 to PJB graduates from 2006 to 2013 , which is $27.48 \%$ of the universe. The findings indicate significant percentage of motivated young people participating in politics, which is in stark contrast to survey data from young people in general. Among graduate males there is no great motivation or interest in party politics either. The main conclusion is that to promote the political education it is necessary to promote trust in the political institutions and stimulates their involvement by changing the disenchantment and deinstitutionalization with the political process.

\section{Keywords}

Youth; Political Participation; Brazilian Young Parliament; Political Parties; Brazilian Chamber of Deputies. 
96 | Antonio Teixeira de Barros e Lúcio Meireles Martins

\section{Introdução}

$\mathrm{O}$ artigo tem como objetivo analisar os impactos do Parlamento Jovem Brasileiro (PJB) na participação política institucional dos egressos via partidos políticos. A pesquisa é guiada pela seguinte indagação: um projeto institucional de simulaçáo parlamentar para jovens pode interferir na disposição dos egressos para maior interesse e motivaçáo para a participação política por meio dos partidos?

Os projetos de simulação parlamentar juvenil são utilizados, atualmente, pelo legislativo federal, pelas assembleias legislativas e por câmaras municipais para proporcionar a jovens estudantes a experiência de conhecer como se desenvolvem as atividades parlamentares. Esses projetos constituem, portanto, um instrumento privilegiado de educação política e de engajamento do público escolar nas questóes políticas da sociedade (COSSON, 2009). Trata-se, segundo o autor, de uma experiência singular de letramento político, ou seja, "o processo de apropriação de práticas, conhecimentos e valores para a manutenção e aprimoramento da democracia" (COSSON, 2008, p. 195).

Pesquisas recentes ${ }^{1}$ indicam que existe um baixo nível de letramento político da população em geral e especialmente dos jovens, não apenas no Brasil. Nos Estados Unidos, por exemplo, 35\% dos alunos do último ano do secundário não alcançam sequer o nível básico de conhecimento na área de educação cívica e apenas $4 \%$ atingiam o nível avançado. Outro estudo revelou que $62 \%$ dos entrevistados não conseguiam nomear os três poderes. Esse baixo nível de conhecimento e elevado desinteresse pela política se repete em diversos países estudados, como Argentina, França, Reino Unido e outros, revelando um déficit cívico (COSSON, 2008; MARTINS, 2012).

Iniciativas que promovem o letramento político, portanto, podem revigorar a cultura política e contribuir para o entendimento dos processos relacionados à formação dos valores políticos. A formação dessa cultura ocorre de forma dinâmica, desde a infância, nas interações entre geraçôes, na escola e na relação com o Estado. Tal perspectiva justifica os esforços empreendidos pela Câmara dos Deputados por meio do Parlamento Jovem Brasileiro (PJB), pois apresenta a educação política como uma alternativa para o fortalecimento dos valores e das práticas democráticas, o que se manifestaria, também, por meio da participação política institucional. Afinal, ao promover o letramento político, o PJB estimula os jovens a se engajarem em movimentos de conotação partidária? A simulação de atividades parlamentares pode

\footnotetext{
${ }^{1}$ Para um inventário dessas pesquisas, consultar Martins (2012).
} 
interferir na confiança em relação aos partidos políticos e no Poder Legislativo? Que efeitos podem ser observados a partir da experiência dos egressos do PJB? Essas são as principais questóes que o artigo tenta responder. Antes, porém, examinamos a literatura sobre juventude e política e uma breve abordagem sobre juventude e política.

\section{Juvetude e Politica}

Embora a juventude seja representada sociologicamente como "uma categoria relacional que posiciona os indivíduos como pertencente a uma dada faixa etária" (GOHN, 2013, p. 205), o que as pesquisas recentes mostram é que existem várias juventudes. Cada vez mais os jovens passam a ser caracterizados como um grupo social plural e emergente (MALFITANO, 2011) ${ }^{2}$, com diferentes formas de engajamento e de participação, variados repertórios de ação coletiva e múltiplas agendas (DAYRELL, MOREIRA e STENGEL, 2011), o que requer olhares menos simplificadores. Isso dificulta a identificação de um padrão de engajamento e de participação, além de apontar para a dificuldade de se registrar tendências uniformes e estanques (RIBEIRO, LANES e CARRANO, 2006).

Uma das características principais da relação entre juventude e política partidária é a desconfiança nas instituiçóes políticas convencionais, visto que tais instituiçóes se apresentam para os jovens "sempre com uma face por demais burocrática e limitadora, estriada, portanto" (NASCIMENTO, 2012, p. 321). Apesar disso, os partidos políticos são reconhecidos como atores fundamentais para a democracia representativa. Os partidos representam a pluralidade ideológica da sociedade, pois oferecem, no âmbito do sistema de representação democrático liberal, as possibilidades de adesão política (PEIRANO, 2011).

Peter Mair (2003) sustenta a tese de que os partidos não estão em decadência, mas sim em transformaçáo e adaptação aos novos contextos. $\mathrm{O}$ autor sugere que os partidos não são mais intermediários entre a sociedade e o Estado, mas o Estado é que passou a exercer a função de mediador entre a sociedade e os partidos. Essa ideia é compartilhada por Manin (2013), Mendonça (2008) e Urbinati (2013). Para esses autores, em linhas gerais, apesar das crises e metamorfoses da democracia e dos

\footnotetext{
${ }^{2}$ Ao mesmo tempo em que impera essa visão plural da juventude sob a ótica sociocultural, a autora alerta que "observa-se uma uniformização da ideia de juventude, considerando-a indistintamente como um grupo único, para o qual se lança o olhar como 'problema político' necessitando de intervenção e de controle" (MALFITANO, 2011, p. 525).
} 
partidos, tais instituições permanecem relevantes e passam por processos de adaptação e reconfiguração atualmente, mas não de decadência ou declínio. Nesses processos de reconfiguração, a juventude pode ser aliada dos partidos, devido a seu potencial criativo e suas formas de percepção do sistema partidário e da democracia representativa.

Nesse sentido, são relevantes os estudos que apontam para os valores políticos que se apresentam como sendo mais atrativos para a juventude no contexto atual. Entre eles, destacam-se aqueles que valorizam as competências individualizadas, a liberdade de iniciativa e de ação, com o reforço do poder de agência do sujeito, o qual passa a ser visto como um analista competente do seu próprio mundo vivido e da sua existência (BAUMAN, 2008). Este é um fenômeno típico do processo civilizatório, a fim de atender à diferenciação das necessidades e demandas sociais (ELIAS, 1987). Trata-se, pois, de um modo de acomodar, na estrutura, as escolhas e preferências dos agentes humanos individuais (GIDDENS, 1991).

Segundo Beck (1994), a busca de soluções biográficas mais adequadas para resolver as contradições sistêmicas do mundo político caracteriza a fase histórica em que vivemos. Isso implica uma nova ênfase na autodeterminação, na autonomia e na liberdade. Para os jovens, tudo isso se traduz na conquista de novos percursos de liberdade e de espaços de ação política. Nesse contexto, conforme Dubet (1998), a experiência social é mais relevante do que os papeis previamente definidos. Para os jovens, existe uma dificuldade de aceitar essa definiçáo prévia de papeis, como modelos rígidos a serem seguidos.

Freire (2009) apresenta um levantamento de pesquisas que confirmam que essa tendência da juventude ao engajamento político com maior flexibilidade de ação está diretamente relacionada com a crescente força das formas de individualização de vida. A individualização condiciona o aparecimento de motivaçóes de caráter pessoal nos jovens para a realização das práticas políticas. Em outras palavras do autor (2009, p. 16), "as diferentes dimensôes do processo de individualização motivam o surgimento de diferentes motivaçóes com um caráter pessoal para a prática associativa".

Teixeira Coelho (1997), ao refletir sobre a cultura política dos jovens, aponta para um novo estatuto político da juventude, marcado pelo imediatismo e as relaçôes diretas: 


\begin{abstract}
As relaçōes preferidas pelos jovens são as que se dão de modo direto e imediato, sem a mediação de alguma coisa ou objeto como a obra de cultura, eventual pretexto para a troca simbólica, e sem a mediação de um agente, como no quadro político-institucional tradicional. O que parece interessar-lhes mais é o que está ao seu redor imediato, ao alcance da vista e do corpo. Esse traço do comportamento jovem reforça outra tese com circulação atual, a da decadência das ideias de delegação e representação, base da forma política republicana clássica (TEIXEIRA COELHO, 1997, p. 160-61).
\end{abstract}

É por essa razão, segundo Augusto (2008, p. 164), que os jovens tendem a olhar a política como 'o que acontece no parlamento' e náo tanto como 'algo que afeta minha vida'. Para o autor, não se trata de apatia, mas de um modo próprio da juventude de se relacionar com os processos democráticos. Desse diagnóstico é que resultariam as crescentes incoerências entre os modelos de ação da política institucionalizada e as práticas sociais, revelando que o poder que as instituiçóes dispóem para dar sentido às biografias individuais está em declínio. Para o autor, é necessário investigar como os jovens produzem a sua relação com os domínios públicos e políticos e que efeitos a atuação deles pode produzir no sistema democrático. Conforme o autor:

a proposta é que o aparente alheamento dos jovens relativamente à política "do palácio" reflete não um apoliticismo, mas um desencantamento/desconfiança relativamente aos mecanismos formais ou convencionais de integração política, que poderá resultar numa desinstitucionalização da ação política juvenil (AUGUSTO, 2008, p. 161).

Nesse processo, segundo o autor, é necessária a ressalva de que os jovens têm se afastado da política institucionalizada, mas não da democracia. Para os jovens, a democracia surge associada a um desejo de liberdade e autonomia que é inteiramente congruente com as perspectivas de renovação da democracia. Por outro lado, o autor salienta que a democracia está mais estreitamente vinculada ao plano existencial dos jovens e não ao plano político. Assim, é necessário "não confundir desinteresse pela política com desinteresse pelos mecanismos formais e institucionais da política, em particular os partidos e as elites que as lideram" (AUGUSTO, 2008, p. 164).

$\mathrm{O}$ engajamento político juvenil nem sempre segue as lógicas de pragmatismo político dos partidos. Na maioria das vezes, é impulsionado pelo idealismo, conforme 
registra pesquisa de Castro (2008). Trata-se de modos de entender a política como um conjunto de perspectivas marcadas pela convergência na defesa de causas comuns, independentemente da orientação ideológico-partidária. Essa convergência é expressa, por exemplo, no combate à corrupçáo, na redução das desigualdades sociais e na reivindicação de melhores serviços públicos, especialmente da educação e saúde. Isso significa que a militância juvenil nos partidos políticos e nos movimentos estudantis é pautada por uma visão crítica da sociedade e pela participação entendida como forma de promover uma ampla transformação social.

Segundo a mesma pesquisa, essa particularidade no modo juvenil de encarar a participação política é um dos fatores que explicam a suspeita deles em relação à política institucionalizada. Além disso, as disputas, os debates e conflitos característicos da esfera partidária, por exemplo, são vistos como impedimentos para o engajamento e a participação no plano institucional, pois implica negociaçóes e acordos suspeitos. Tais arranjos são considerados instrumentos para a máquina partidária, algo que se distancia do ideal de transformação sociopolítica almejada. Por essa razão, os jovens preferem "uma via direta de ação e de participação na sociedade, em que podem constatar, por eles mesmos, os efeitos do que fazem, sem intermediaçôes" (CASTRO, 2008, p. 263).

Dados da Pesquisa Nacional sobre o Perfil e a Opinião dos Jovens Brasileiros ${ }^{3}$ mostram que $54 \%$ deles nunca participaram de nenhuma atividade política no âmbito institucional e que $45 \%$ reconhecem as mobilizaçóes de rua, protestos, manifestaçóes e outras açóes diretas como a via mais indicada para a solução de problemas sociais. Outros levantamentos mostram até $82 \%$ de desinteresse dos jovens pela política em suas modalidades institucionalizadas ${ }^{4}$ (BAPTISTA et al., 2013). Pesquisa realizada pelo Instituto Data Popular, em 2014, revela que 59\% dos jovens brasileiros acreditam que o Brasil seria melhor se não houvesse nenhum partido político (RODRIGUES, 2014). Apesar da descrença, a pesquisa revela que a juventude é mais informada que seus pais e tem peso decisivo na eleição.

Considerando que a educação também contribui para a socialização política (CASTRO, 2009), caberia indagar até que ponto uma iniciativa de educaçáo para a democracia, como é o caso do PJB, pode influenciar a conduta de jovens? Que

\footnotetext{
3 Pesquisa realizada pela Secretaria Nacional da Juventude. Disponível em: http://www.polis.org.br/uploads/1982/1982.pdf.

${ }^{4}$ Trata-se da pesquisa Juventude, Participação e Voto realizada por pesquisadores da Universidade Federal de Minas Gerais, em 2010. Disponível em: http://www.opiniaopublica.ufmg.br/pesquisas_detalhe.php?id=41.
} 
aspectos podem ser afetados no que se refere à participação política institucional? Os conhecimentos e a experiência adquirida no PJB diferenciam o comportamento dos egressos em relação ao perfil dos cidadãos verificado em estudos semelhantes?

\section{O Parlamento Jovem Brasileiro}

O PJB é um projeto anual de simulação parlamentar juvenil. Estudantes do ensino médio e técnico integrado ao médio de escolas públicas e privadas, entre $16 \mathrm{e}$ 22 anos (a partir do $2^{\circ}$ ano), sáo convidados a participarem de um concurso de projetos de lei, por meio do qual são selecionados 78 jovens que terão a oportunidade de passar por um processo de formação e prática parlamentar simulada, durante cinco dias, na Câmara dos Deputados.

A iniciativa foi idealizada pelo entáo Deputado Federal Lobbe Netto (PSDB/SP) e instituído como um projeto institucional da Câmara dos Deputados por meio da resoluçáo 12/2003. Em novembro daquele ano, previa-se inicialmente um projeto a ser desenvolvido em parceria com as instituiçóes representativas estudantis (UNE e UBES) que promoveriam a seleção por meio de eleiçôes abertas aos estudantes. Percebe-se assim que o objetivo inicial do projeto era de formar líderes políticos, dada essa intenção de se vincular ao movimento estudantil. Também se previa alternância de turmas do ensino médio e do ensino superior a cada ano 5 . Porém, já na primeira ediçâo do projeto, em 2004, foi iniciado com outra configuraçáo, bastante semelhante com o formato atual, direcionado aos jovens do ensino médio e técnico integrado e com seleção realizada por meio de concurso de redação de projetos de lei. Apesar de alteraçóes pontuais de procedimentos, seja na seleção ou nas atividades didáticas e de simulação, o projeto vem tendo uma constância de seus procedimentos e conteúdos, o que facilita uma análise histórica dos seus resultados. Desde que foi criado, o PJB já realizou doze ediçóes (2004 a 2015).

Apesar de não ter se efetivado a participação das instituiçóes estudantis, uma das características do projeto está no envolvimento interinstitucional. O Conselho Nacional de Secretários de Educação (CONSED) tem papel essencial na difusão do programa nacionalmente. As secretarias estaduais realizam a divulgação do projeto por meio de releases pré-elaborados, spots de rádio e peças publicitárias impressas,

\footnotetext{
${ }^{5}$ Regimento interno do PJB ainda mantém essas intençóes iniciais apesar das modificaçóes por que passaram o projeto: http://www2.camara.leg.br/responsabilidade-social/parlamentojovem/regimentointerno-do-parlamento-jovem-brasileiro.
} 
oferecidos pela Câmara dos Deputados, e recebem as inscriçôes com os projetos de lei para uma primeira avaliação de questóes documentais obrigatórias. $\mathrm{O}$ servidor indicado por cada secretaria de educação também faz uma primeira seleção dos projetos com base em critérios pré-estabelecidos e os escolhe em até quatro vezes a quantidade de vagas de cada estado. A seleçáo final dos projetos é feita por uma comissão de servidores da Câmara dos Deputados designados anualmente. No primeiro semestre de cada ano, é realizado um encontro com os representantes das secretarias de educação dos estados com objetivos de: avaliar a edição anterior, conscientizar quanto à importância da educação política, buscar o compromisso com as etapas de organizaçáo do programa e apresentar a campanha de divulgaçáo da edição seguinte.

O método do projeto é baseado no protagonismo juvenil; assim, as atividades formativas funcionam como um suporte imediato para a atuação do jovem na defesa de sua proposta e no debate das propostas dos demais parlamentares. A simulação inclui eleição da Mesa Diretora, capacitação sobre noções de análise orçamentária, debate e votação dos projetos de cada jovem nas comissóes temáticas, além de votação em plenário das proposiçôes selecionadas pelas Comissôes e pelo Colégio de Líderes, sendo todas as atividades organizadas conforme o Regimento Interno do PJB, homologado pelo Ato da Mesa Diretora da Câmara no 49/2004 .

\section{Análise dos dados}

A análise está baseada em levantamento do tipo survey, com questionário aplicado online nos meses de outubro e novembro de 2014. Os ex-participantes das ediçóes de 2004 a 2013 (10 eventos) foram contatados por meio de e-mail e Facebook, quando foram convidados a preencher um questionário com questóes abertas e fechadas. Do total de 759 jovens que participaram do projeto nas dez ediçóes mencionadas, 173 responderam o questionário, representando 22,79\% do universo estudado. Dada a técnica de coleta escolhida (survey pela internet) ser praticamente o único meio viável de contato com os egressos de todas as ediçóes, o levantamento não foi precedido por estratificação e cálculo de amostragem, pois intentou-se o maior número de respostas possíveis com amostra por conveniência.

\footnotetext{
6 Legislação interna da Câmara dos Deputados disponível em: http://www2.camara.leg.br/legin/int/atomes/2004/atodamesa-49-25-outubro-2004-534831normaatualizada-cd.html.
} 
Ao final da coleta de dados, optou-se pela exclusão das respostas relativas aos dois anos iniciais (2004 e 2005) em vista do baixo índice de respostas. Dessa forma, a análise final contempla oito anos do PJB, isto é, de 2006 a 2013, totalizando 166 respondentes, o que corresponde a $27,48 \%$ do total de egressos das oito ediçóes mencionadas. Essa decisão foi tomada baseando-se nas diversas características desse público analisado no estudo, entre elas: gênero, idade, moradia em capital ou cidade do interior e escolaridade ${ }^{7}$, já que a análise de uma amostra com apenas duas (2004) ou cinco (2005) respostas não abarcaria esses variados fatores que podem influenciar as variáveis analisadas. Um fator que oferece confiança na qualidade dos dados obtidos é a semelhança entre os percentuais populacionais dos estados e a proveniência dos respondentes, o que reforça a representatividade da amostra estudada quanto ao universo de egressos. É necessário ponderar que a realizaçáo do estudo por meio de survey online pode diminuir essa diversidade da amostra, possivelmente excluindo do levantamento os jovens com menor renda e com dificuldades de acesso a computadores e à internet.

\section{Perfil dos respondentes}

A análise dos dados inicia-se com a caracterização da amostra estudada, com ênfase para os seguintes aspectos: faixa etária dos respondentes, sexo, ano de participação, região e escolaridade. O objetivo dessas informaçôes é contextualizar as respostas dos sujeitos da pesquisa.

A amostra estudada inclui participantes de 17 a 29 anos, sendo cerca de $48 \%$ mulheres e $52 \%$ homens (Tabela 1 ).

Tabela 1 - Perfil de idade e sexo da amostra

\begin{tabular}{c|c|c|c|c|c|c|c}
\hline Faixa etária & Amostra & $\mathbf{\%}$ & Sexo & Egressos & \% & Amostra & $\%$ \\
\hline 17 a 20 & 64 & 38,55 & Masculino & 295 & 48,84 & 86 & 51,81 \\
\hline 21 a 24 & 77 & 46,38 & Feminino & 309 & 50,66 & 80 & 48,19 \\
\hline 25 a 29 & 25 & 15,06 & -------- & ---- & ----- & --- & ----- \\
\hline Total & 166 & 100 & ------- & 604 & 100 & 166 & 100 \\
\hline
\end{tabular}

Fonte: Elaboração dos autores.

\footnotetext{
${ }^{7}$ Não foram analisados fatores socioeconômicos, pois essa questão poderia prejudicar o levantamento de dados devido ao constrangimento que acarretaria na coleta. Outro fator náo estudado foi a proveniência dos egressos de escolas públicas ou particulares, já que os ex-participantes das edições mais antigas passaram por outras instituiçôes também públicas ou privadas como universidades e outras instituiçóes de ensino, o que inviabilizaria uma análise isolada dessa característica.
} 
Do ponto de vista da faixa etária, predominam os respondentes entre 21 e 24 anos, com 77 registros, equivalente a 46,38\%. Quanto à relação entre o percentual de masculinos e femininos, os dados são próximos da proporção de eleitores (48\%) e eleitoras (52\%), segundo dados do Tribunal Superior Eleitoral ${ }^{8}$. Quanto à distribuição por ano, a Tabela 2 mostra um relativo equilíbrio no número de respondentes de cada uma das ediçóes do PJB, com o percentual mínimo de 19,48\% em 2010 e o máximo de 40,50\% em 2013. Mesmo quando se trata dos percentuais menores, a amostragem obtida é relevante.

Tabela 2 - Amostra e população das ediçôes estudadas do PJB

\begin{tabular}{c|c|c|c}
\hline Edição & Populaçáo & Amostra & Percentual \\
\hline 2006 & 78 & 17 & $21,79 \%$ \\
\hline 2007 & 77 & 29 & $37,66 \%$ \\
\hline 2008 & 78 & 20 & $25,64 \%$ \\
\hline 2009 & 65 & 17 & $26,15 \%$ \\
\hline 2010 & 77 & 15 & $19,48 \%$ \\
\hline 2011 & 81 & 20 & $24,69 \%$ \\
\hline 2012 & 70 & 16 & $22,85 \%$ \\
\hline 2013 & 78 & 32 & $41,02 \%$ \\
\hline Total & 604 & 166 & $27,48 \%$ \\
\hline
\end{tabular}

Fonte: Elaboração dos autores.

Os egressos respondentes residem em grande parte em cidades do interior ${ }^{9}$ (64\%) e os demais em capitais, com predomínio de residentes nas regióes Sudeste, Nordeste e Sul, respectivamente, como mostra a Tabela 3. A amostragem de participantes segmentada conforme a regiáo geográfica é relativamente coerente com a distribuição do eleitorado regional ${ }^{10}$. A quantidade de vagas do projeto é proporcional ao quantitativo de cadeiras na Câmara dos Deputados que, por sua vez,

\footnotetext{
8 Em http://www.tse.jus.br/eleitor/estatisticas-de-eleitorado/estatistica-do-eleitorado-por-sexo-e-faixaetaria.

${ }^{9}$ As cidades foram classificadas em capital ou cidade de interior, sem uma análise mais detalhada do tamanho das cidades. Cidades de regiôes metropolitanas das capitais, quando nomeadas diretamente foram consideradas cidades do interior, pois isso indicaria uma vinculação maior à localidade do que à metrópole.
}

${ }^{10}$ Disponível em: http://www.tse.jus.br/eleitor/estatisticas-de-eleitorado. 
está vinculada à população dos estados brasileiros. Conforme pode ser verificado na Tabela 3, a realização da pesquisa resultou numa proporção muito próxima entre a amostra e a proporção da população das regiôes. Considera-se, assim, que os dados levantados têm uma boa representatividade do perfil da população estudada (egressos do PJB).

Tabela 3 - Comparação da amostra dos egressos e população das regiōes

\begin{tabular}{c|c|c|c|c|c|c}
\hline Regiáo & $\begin{array}{c}\text { Amostra } \\
\text { por } \\
\text { regiáo }\end{array}$ & $\begin{array}{c}\text { Total de } \\
\text { egressos } \\
\text { por regiăo }\end{array}$ & $\begin{array}{c}\text { Amostra } \\
\text { em relaçáo } \\
\text { ao total de } \\
\text { egressos }\end{array}$ & $\begin{array}{c}\text { Populaçáo } \\
\text { brasileira } \\
\text { por regiáo }\end{array}$ & $\begin{array}{c}\text { Eleitores } \\
\mathrm{N}\end{array}$ & $\begin{array}{c}\text { Eleitores } \\
\%\end{array}$ \\
\hline Norte & 15 & 74 & $8,44 \%$ & $8,88 \%$ & 10.704 .517 & $7,55 \%$ \\
\hline Sudeste & 66 & 207 & $39,75 \%$ & $40,83 \%$ & 61.233 .192 & $43,21 \%$ \\
\hline $\begin{array}{c}\text { Centro- } \\
\text { Oeste }\end{array}$ & 19 & 46 & $7,45 \%$ & $11,24 \%$ & 10.266 .708 & $7,24 \%$ \\
\hline Nordeste & 39 & 184 & $27,75 \%$ & $23,67 \%$ & 38.388 .087 & $27,09 \%$ \\
\hline Sul & 26 & 93 & $14,32 \%$ & $15,38 \%$ & 20.810 .471 & $14,68 \%$ \\
\hline Exterior & 1 & 0 & $0,60 \%$ & $\mathrm{~N}^{*}$ & 296.157 & $0,2 \%$ \\
\hline Total & 166 & 604 & 100 & 100 & 141.699 .132 & 100 \\
\hline
\end{tabular}

Fonte: Elaboração dos autores, com informaçôes complementares da Justiça Eleitoral (2014).

Em relaçáo à formaçáo educacional dos egressos, grande parte dos respondentes está em processo de graduação ou já se formaram ${ }^{11}$ (68,67\%). Quando se separa apenas aqueles graduados ou graduandos em ciências humanas ou sociais aplicadas chega-se a um percentual de $47,59 \%$ do geral da amostra.

Tabela 4 - Escolaridade dos egressos

\begin{tabular}{c|c|c}
\hline Formação & Quantitativo de respostas & Proporçóes da amostra \\
\hline Médio e técnico & 33 & $19,87 \%$ \\
\hline Graduação & 114 & $68,67 \%$ \\
\hline Pós-graduação & 19 & $11,44 \%$ \\
\hline Total & 166 & 100 \\
\hline
\end{tabular}

Fonte: Elaboraçáo dos autores.

${ }^{11}$ Cabe ressaltar que os dados se referem ao momento em que os egressos responderam o questionário e não ao período em que participaram do PJB. 


\section{Relacionamento dos egressos com os partidos politicos}

Apresenta-se a seguir a Tabela 5 com o resumo dos principais tipos de relacionamento verificados entre os egressos com os partidos políticos em termo de participação institucional, considerados aqui como filiação partidária e envolvimento em atividades de militância partidária.

Tabela 5 - Relacionamento dos egressos com partidos políticos

\begin{tabular}{c|c}
\hline Tipo de relacionamento & Percentual ${ }^{\mathbf{1 2}}$ \\
\hline Nunca foi filiado a um partido político & $69 \%$ \\
\hline Estavam filiados a um partido político na data da pesquisa & $24 \%$ \\
\hline Já possuíam vínculo partidário antes do PJB (filiação ou pré-filiação jovem) & $10 \%$ \\
\hline Declararam ter se filiado após o PJB, mas interromperam a participação & $7 \%$ \\
\hline Filiaram-se a um partido após o PJB & $21 \%$ \\
\hline Participavam de militância partidária na data da pesquisa & $23 \%$ \\
\hline $\begin{array}{c}\text { Participaram de militância partidária apenas pós-PJB, mas interromperam essa } \\
\text { atividade }\end{array}$ & $10 \%$ \\
\hline
\end{tabular}

Fonte: elaboraçáo dos autores.

Como forma de comparar esse nível de participaçáo dos egressos em partidos políticos, a pesquisa "Juventude, Juventudes: o que une e o que separa" empreendida pela Unesco em 2004, com amostragem nacional, apontou que apenas 3,3\% dos jovens (15 a 29 anos) já havia participado de alguma atividade partidária (ABRAMOVAY e CASTRO, 2006).

Atualmente, o Brasil tem 10,71\% de seus eleitores filiados a algum partido político (BRASIL, 2014) considerando-se todas as idades. Esse percentual é muito próximo daquele verificado em relação ao período anterior à participaçáo dos egressos, entretanto, essa comparação deve ser relativizada já que o recorte de idade dos participantes na data da realização da pesquisa variou de 17 a 29 anos, já a dos eleitores engloba dos 16 anos ao eleitor mais idoso, ou seja, é possível identificar um nível de participação política diferenciado desse grupo que se inscreve e chega ao PJB, tanto em relação à filiação partidária como à militância política. Quando perguntados acerca de qual partido político encontra-se filiado ou por qual já foi inscrito, 42 $(45,30 \%)$ jovens indicaram partidos políticos e um deles indicou a Uniáo da Juventude Socialista (associação civil).

\footnotetext{
${ }^{12}$ Percentuais arredondados para mais quando a casa decimal for maior do que meio ponto percentual e para menos quando igual ou menor.
} 
Os partidos com mais filiados foram o PT (18), PSDB (6), PCdoB (4), PMDB (2) e DEM (2). Outros 10 partidos foram citados por 1 jovem cada, totalizando-se 15 partidos citados, o que é reflexo da fragmentação político-partidária do país, o que se comprova pela existência de 28 partidos (bancada na eleição) com representantes na atual 55a Legislatura (2015-2019) na Câmara dos Deputados, sendo seis a mais do que na legislatura anterior. Esse quadro de filiaçóes apresenta relação com o que Pippa Norris (2003) denomina de "efeito de período", o que pode ser percebido tanto pela fragmentação partidária e também na maior quantidade de filiados no partido que governa o país desde 2002 (PT) e pelo segundo mais citado ser justamente o principal partido de oposiçáo (PSDB).

A participação partidária é maior entre os homens, pois 31\% deles afirmaram estar filiados, enquanto que $16 \%$ das mulheres. Quando perguntados acerca de participação em militância partidária (o que não exige filiação), essa diferença se amplia, já que $11 \%$ delas se consideram participantes militantes e $35 \%$ dos homens. Quanto à residência (capital ou interior), percebe-se maior percentual de filiados (atualmente) nas cidades do interior 27\%, enquanto que 19\% dos filiados residem nas capitais. Em proporção semelhante à filiação, a atividade de militância também é um comportamento atual indicado por $25 \%$ entre os residentes no interior, enquanto que $21 \%$ residentes nas capitais afirmaram participar desse tipo de atividade política.

A análise do nível educacional cruzado com a filiação partidária apresenta uma leve variaçáo no quantitativo dos atualmente filiados, sendo que $31 \%$ daqueles com nível médio ou técnico são atualmente inscritos em algum partido político, enquanto que $20 \%$ daqueles no nível de graduação ou pós-graduação confirmaram o registro partidário. A análise da atividade de militância indica que aqueles egressos que chegaram à pós-graduação tiveram maior interrupção dessa atividade após o projeto ( $15 \%$ desse grupo) e tem uma menor proporção de jovens militantes do que nos demais níveis, indicando uma possível concorrência dessas atividades (formaçáo educacional e militância). A análise de outra variável 'interesse em se candidatar' apresentada neste estudo também reforça essa possível concorrência da formação acadêmica e da atuação na política partidária.

\section{Motivação para a participação na politica partidária}

Foi perguntado para o egresso: "Em relação à sua atual motivação para participar da política de forma institucionalizada, por meio de partidos políticos, você se considera: totalmente motivado, penso seriamente, pouco motivado ou sem 
motivação". O Gráfico 1 a seguir demonstra a porcentagem das respostas em relação a cada ano, além do total para os oito grupos analisados. De forma semelhante a outras temáticas do estudo, essa motivação é maior no primeiro ano decorrido da interação com o PJB (considerando-se os dois níveis mais fortes somados), já para os anos seguintes há uma diminuição da motivação e percebe-se certa constância desses maiores níveis somados em torno de 40 a 50\%. O nível educacional dos egressos não apresentou relação relevante com essa motivação, porém é possível perceber um maior quantitativo de egressos formados ou formandos em ciências humanas ou sociais aplicadas que tem maior interesse pela política institucional, conforme pode ser verificado no próximo quesito analisado (interesse em se candidatar a cargos políticos).

Gráfico 1 - Motivação para participar de partidos políticos

\begin{tabular}{|c|c|c|c|c|c|c|c|c|c|}
\hline \multicolumn{10}{|l|}{$100 \%$} \\
\hline $90 \%$ & & & & & & & & & \\
\hline $80 \%$ & & & & & & & & & \\
\hline $70 \%$ & & & & & & & & & \\
\hline $60 \%$ & & & & & & & & & \\
\hline $50 \%$ & & & & & & & & & \\
\hline $40 \%$ & & & & & & & & & \\
\hline $30 \%$ & & & & & & & & & \\
\hline $20 \%$ & & & & & & & & & \\
\hline $10 \%$ & & & & & & & & & \\
\hline $0 \%$ & 2006 & 2007 & 2008 & 2009 & 2010 & 2011 & 2012 & 2013 & Geral \\
\hline - Totalmente motivado & $17,65 \%$ & $20,69 \%$ & $20 \%$ & $23,53 \%$ & $33,33 \%$ & $25 \%$ & $31,25 \%$ & $25 \%$ & $24,10 \%$ \\
\hline Penso seriamente & $41,18 \%$ & $27,59 \%$ & $35 \%$ & $35,29 \%$ & $26,67 \%$ & $30 \%$ & $25 \%$ & $43,75 \%$ & $33,73 \%$ \\
\hline Pouco motivado & $23,53 \%$ & $44,83 \%$ & $25 \%$ & $23,53 \%$ & $13,33 \%$ & $30 \%$ & $43,75 \%$ & $25 \%$ & $29,52 \%$ \\
\hline Sem motivação & $17,65 \%$ & $6,90 \%$ & $20 \%$ & $17,65 \%$ & $26,67 \%$ & $15 \%$ & $0 \%$ & $6,25 \%$ & $12,65 \%$ \\
\hline
\end{tabular}

Fonte: Elaboração dos autores.

Quando se analisa a motivação cruzada com a moradia dos egressos (interior ou capital) verifica-se pouca diferença, sendo que $61 \%$ dos egressos residentes nas capitais encontram-se nos dois maiores níveis motivacionais enquanto que os das cidades do interior $56 \%$ afirmaram ter alto nível de motivação para participar de partidos. A tendência de maior participaçáo masculina verificada no parâmetro filiação partidária também se confirma na motivação para participar de partidos. A maioria dos homens encontra-se nos dois maiores níveis de motivação (71\%), já entre 
as mulheres a maior parte concentra-se nos dois menores níveis (56\%), conforme exposto no Gráfico 2. Ao se cruzar a motivação com a escolaridade percebe-se pouca variação, diferentemente da característica de gênero. No fator educação, aqueles com os dois maiores níveis de motivação somados tem o seguinte nível educacional: médio e técnico (58\%), graduação (59\%) e pós-graduação $(53 \%)$.

Gráfico 2 - Motivação para participar de partidos por sexo

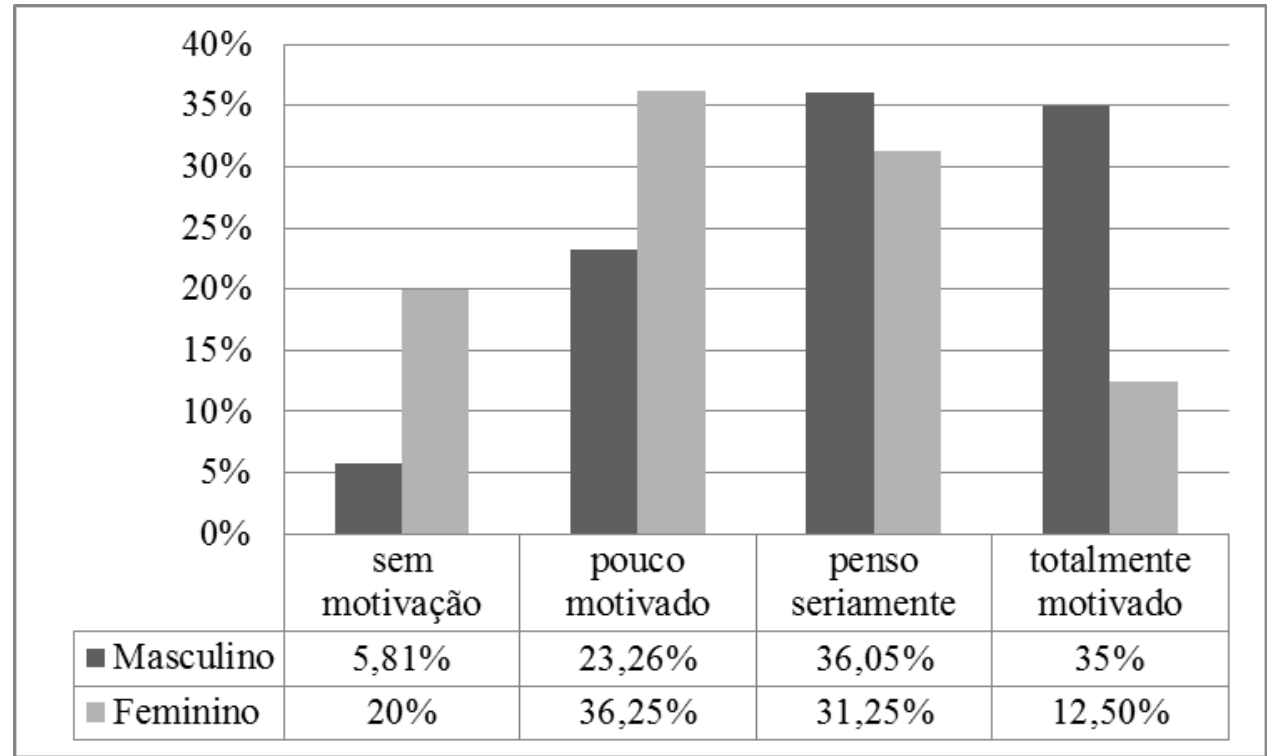

Fonte: Elaboração dos autores.

O fator idade apresentou, em relação à motivação para participar de partidos, resultados bastante variados, sem seguir uma tendência única, como se verifica no Gráfico 3. Interessante destacar a predominância de altos níveis de motivação nos jovens de 17 e 18 anos, que participaram do projeto nas duas últimas ediçóes entre as analisadas (2012 e 2013), fator que, em grande medida, aparenta ter uma permanência com o amadurecimento dos egressos, apesar da queda acentuada entre os respondentes de 18 e 19 anos. Esse mesmo recorte de idade e das ediçóes quanto ao interesse em candidaturas pode ajudar a entender esse fenômeno. 
Gráfico 3 - Motivação para participar de partidos por idade ${ }^{13}$

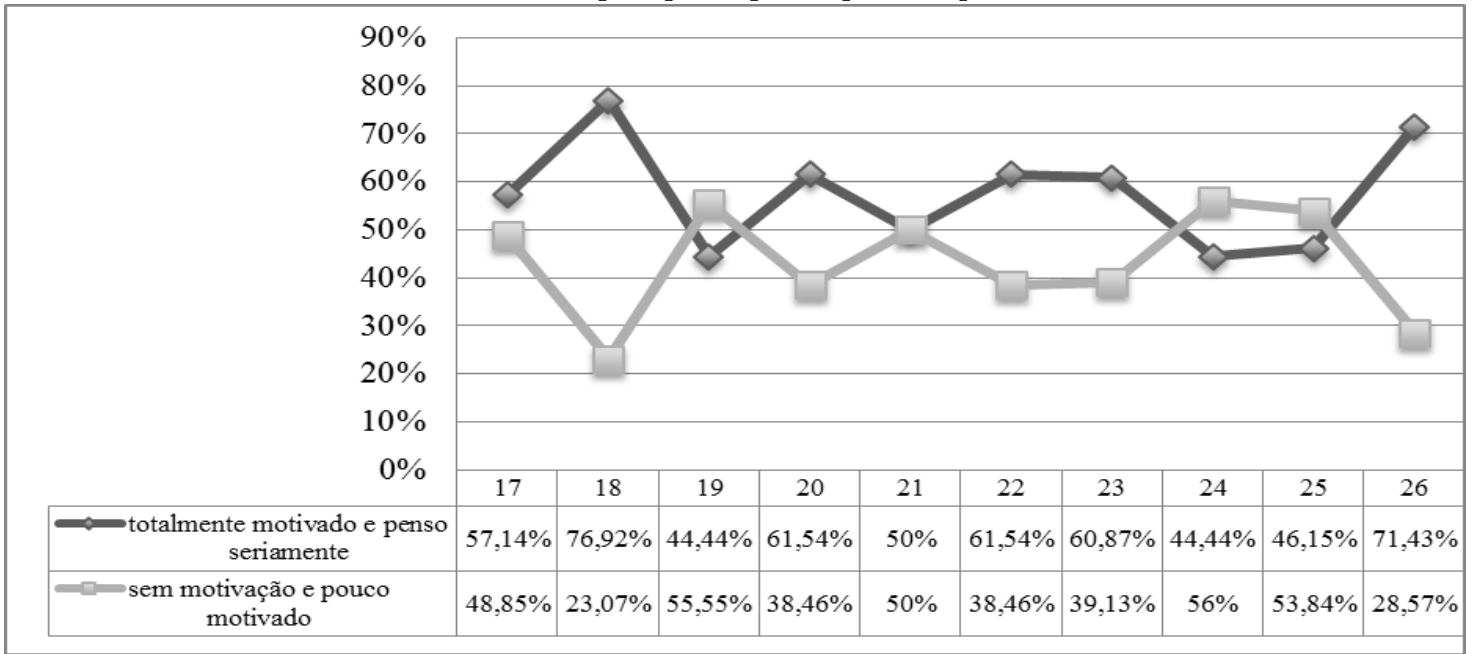

Fonte: Elaboração dos autores.

\section{Estímulo do PJB ao interesse para candidatura a cargos politicos}

Foi perguntado se o PJB havia gerado interesse no participante para se candidatar, com alternativas binárias (sim ou não), sendo que aproximadamente $38 \%$ dos egressos responderam positivamente. No gráfico a seguir, fica clara uma forte diminuição desse estímulo com o passar dos anos transcorridos da participação, tendo a turma mais recente (2013) apontado cerca de 53\% de jovens estimulados, já no último ano analisado (2006) apenas 18\% confirmaram este estímulo, conforme ilustrado no Gráfico 4.

\footnotetext{
${ }^{13}$ Para a análise desse gráfico, é relevante destacar que as idades de 27 a 29 anos representam resposta única ou de apenas dois respondentes; por essa razão, esses pontos apresentaram resultados extremos, o que motivou a exclusão desses dados no Gráfico 3. O menor quantitativo de respondentes de mesma idade são 7 egressos (na faixa de 17 e de 26 anos) e o maior é de 25 egressos (com a idade de 24 anos).
} 
Gráfico 4 - Interesse em se candidatar gerado pelo PJB por edição

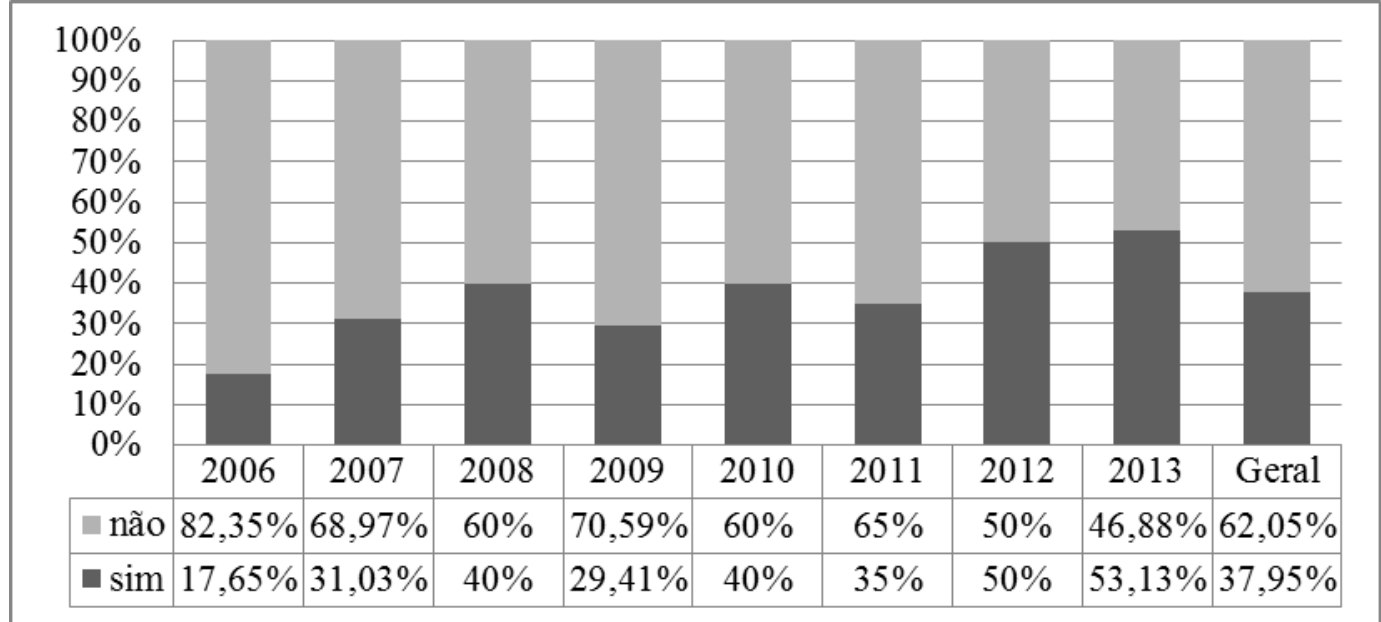

Fonte: Elaboração dos autores.

O público masculino demonstrou maior estímulo para candidaturas com mais de $51 \%$ de respostas positivas, contra cerca de $24 \%$ de respostas para o público feminino, confirmando novamente a tendência de menor participação e interesse pela política institucionalizada entre as mulheres, como mostram os dados do Gráfico 5. De forma semelhante ao quesito motivação para participar de partidos, o parâmetro moradia também indicou um interesse levemente superior para os residentes nas capitais, $42 \%$ contra $36 \%$ entre os que residem no interior. Entretanto, essa diferença do interesse em candidaturas por moradia se contrapóe com os quesitos de filiação partidária e militância que foram mais encontrados em residentes de cidade do interior do que nas capitais. 
112 | Antonio Teixeira de Barros e Lúcio Meireles Martins

Gráfico 5 - Estímulo à candidatura por sexo

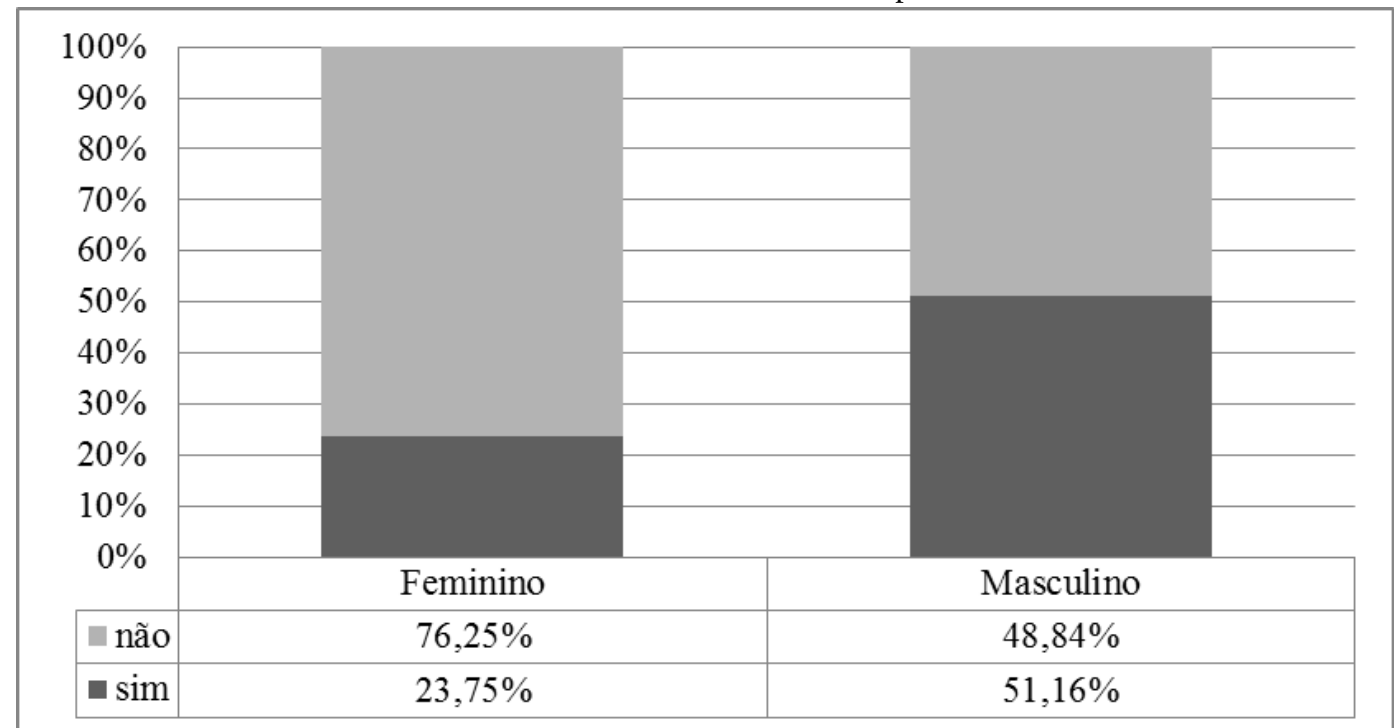

Fonte: Elaboração dos autores.

Quanto maior o nível de formação, menor foi a indicação de estímulo à candidatura, seguindo também a lógica de maior tempo decorrido da participação no projeto e menor interesse, como se vê no Gráfico 6. Entre os graduados de nível superior, nas três grandes áreas de formação (exatas, humanas e biológicas), existe um relevante interesse dos egressos da área de humanas, sendo que mais de $40 \%$ desse grupo indicou ter se estimulado a se candidatar. Já entre os estudantes da área de exatas, $28 \%$ relataram esse interesse e, daqueles da área de biológicas, apenas $21 \%$. 
Gráfico 6 - Estímulo à candidatura por escolaridade

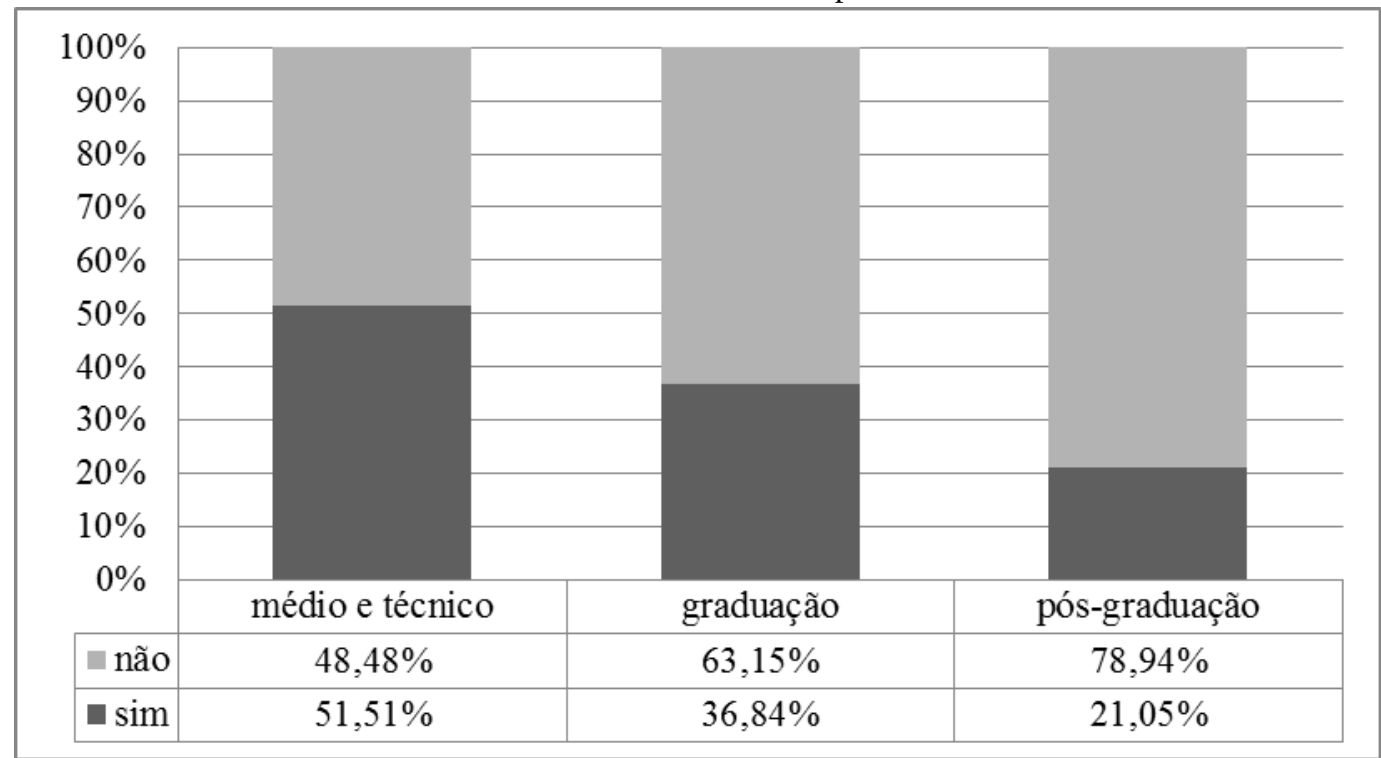

Fonte: Elaboração dos autores.

Quanto maior a idade do egresso, menor foi a indicação do interesse em se candidatar como um efeito da participação no PJB, conforme demonstrado no Gráfico 7. Esse resultado se contrapóe em certa medida à teoria de que os jovens se interessariam menos por política e, conforme aumentaria o nível educacional e a aquisição de recursos cognitivos e vínculos sociais, o interesse aumentaria (OKADO, 2013). Pelo contrário, percebe-se um decréscimo desse interesse quando se aumenta o nível educacional, o que não é dado suficiente para contrapor a teoria geracional do interesse pela política, mas apontaria para uma diminuição do efeito de estímulo à participação institucional e eleitoral com a maior escolarização, fator que pode ser concorrente em relação às atividades político partidárias. 
114 | Antonio Teixeira de Barros e Lúcio Meireles Martins

Gráfico 7 - Estímulo à candidatura por idade ${ }^{14}$

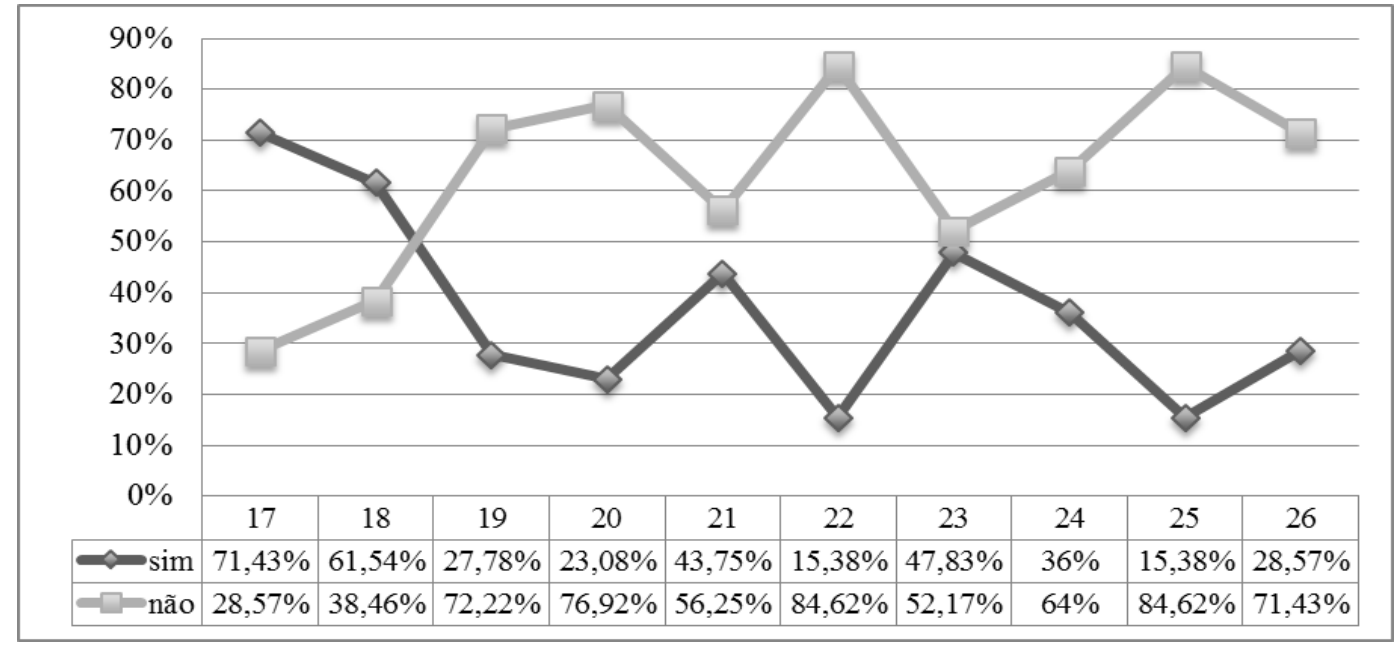

Fonte: Elaboração dos autores.

\section{Confiança nos partidos politicos}

Outra temática da pesquisa em questáo, que pode auxiliar a explicação desse fenômeno, é o nível de confiança dos egressos nos partidos políticos, já que esse é um fator preponderante no sentido de estimular ou desestimular a participaçáo política institucionalizada. Foi perguntado aos egressos qual seria o nível de confiança que eles teriam antes de participar do projeto e qual o nível após o PJB (com alternativas nenhuma, quase nenhuma, alguma e muita confiança). Para cerca de $49 \%$ dos respondentes, a confiança aumentou, $42 \%$ mantiveram-se como antes e outros $9 \%$ declararam que diminuiu sua confiança nos partidos. Mais uma vez, percebe-se um impacto positivo do $\mathrm{PJB}$, ao gerar uma maior confiança numa instituiçâo que é parte integrante do sistema representativo na democracia. Para melhor compreensão desses dados, é necessário o seu cruzamento com a motivação para participar de partidos.

Tabela 6 - Cruzamento das respostas sobre confiança política e motivação para participar de partidos

\begin{tabular}{c|c|c}
\hline & \multicolumn{2}{|c}{ Motivação para participar de partidos políticos } \\
\hline Confiança nos partidos políticos & $\begin{array}{c}\text { Sem motivaçáo e } \\
\text { pouca motivação }\end{array}$ & $\begin{array}{c}\text { Penso seriamente e totalmente } \\
\text { motivado }\end{array}$ \\
\hline Nenhuma e quase nenhuma confiança & $20,48 \%$ & $11,45 \%$ \\
\hline Muita e alguma confiança & $21,69 \%$ & $46,39 \%$ \\
\hline
\end{tabular}

Fonte: Elaboração dos autores.

${ }^{14}$ Foi utilizado o mesmo critério do gráfico 3, excluindo-se as respostas únicas ou duplas das idades de 27 a 29 anos. 
Grande parte dos egressos que tem maior confiança nos partidos políticos tem também maior nível de motivação para participar dessas instituiçóes. Essa afirmação se baseia no cruzamento dos dois maiores níveis de confiança com os dois maiores de motivação, que, somados, representam mais de $46 \%$ dos respondentes. A inversão dos quesitos também abarca parte considerável dos egressos. Assim, aqueles com menor motivação e menor confiança reúnem $20 \%$. Os que possuem menor confiança junto aos que, ao contrário, tem maior motivação, somam apenas cerca de $11 \%$. Em contraponto, verifica-se um percentual de praticamente $22 \%$ de egressos que se encontram nos dois maiores níveis de confiança nos partidos; porém, também indicaram estar pouco ou sem qualquer motivação para essa ação. Para efeito de confirmaçáo estatística dessa tendência, a correlação ${ }^{15}$ destes dois parâmetros indicou o índice de 0,28 , o que confirma uma leve tendência positiva de associação entre esses fatores, reforçando essa relação entre confiança e motivação de participar da política de forma institucionalizada, de modo a corroborar, em certa medida, preceito clássico da cultura cívica (ALMOND e VERBA, 1989; NORRIS, 2003).

O Índice de Confiança Social (ICS), elaborado pelo IBOPE, desde 2009, indica os partidos políticos como a instituição com menor credibilidade entre os cidadãos brasileiros, sendo que, numa escala de 100 pontos, em 2014, obteve 30. Como forma de comparação destes dados com o nível de confiança dos jovens egressos em relaçáo aos partidos e os 4 níveis sugeridos por este estudo, quando transpostos para uma escala numérica de 100 pontos $^{16}$, o nível médio encontrado para o período é 39,3 (antes do PJB), o que, para o período posterior, aumenta consideravelmente para 56,8 pontos, aproximando a confiança nos partidos políticos a outras instituiçôes verificadas no índice do IBOPE como 'meios de comunicação' (54), escolas públicas (56) e forças armadas $(62)^{17}$.

Apesar das diferenças metodológicas e de escala na verificação da confiança da população em geral e do PJB, fica evidente uma larga diferença dos resultados do índice e da confiança dos egressos, apontando tanto para um possível perfil

\footnotetext{
${ }^{15} \mathrm{O}$ índice de correlação varia de $-1 \mathrm{a}+1$. Foi utilizada a fórmula CORREL do Excel para o cálculo.

${ }^{16}$ Foi utilizada a mesma escala do IBOPE que considera nenhuma igual a 0 pontos, pouca 33,33, alguma 66,66 e muita 100 .

17 Dados do ICS do IBOPE de 2015, disponível em: http://www.ibope.com.br/pt$\mathrm{br} /$ noticias/Paginas/Ap\%C3\%B3s-queda-acentuada-em-2013, Indice-de-Confianca-Social-seestabiliza.aspx .
} 
diferenciado dos participantes antes do projeto e um reforço gerado pela participação na simulação do Parlamento Jovem Brasileiro.

\section{Conclusões}

É possível afirmar que o Parlamento Jovem Brasileiro interfere significativamente na confiança em relação aos partidos políticos, o que também se relaciona com a maior motivação identificada para participar de açôes partidárias e de militância nessas entidades. A falta de conhecimento acerca do perfil anterior desses participantes dificulta a confirmação empírica de alguns fenômenos analisados; porém, uma simples comparação do perfil do eleitorado em geral com as opiniôes e interesses dos egressos pode nos dar pistas para o entendimento dos efeitos do projeto. Pesquisa do Senado Federal (BRASIL, 2014) com amostragem nacional apontou que $15 \%$ da população já pensou seriamente em se candidatar e outros $3 \%$ já se candidataram. Ao observar que $37,87 \%$ dos egressos afirmaram que o projeto gerou interesse em candidaturas a cargos políticos, já é possível visualizar ampla diferença, o que é reforçado pela diferença do corte etário desses levantamentos.

Enquanto estudos apontam que apenas $1,4 \%$ de jovens ingressam em partidos (TELLES e DIAS, 2010) e que há o desinteresse pela política institucionalizada por $82 \%$ desse público (BAPTISTA et al., 2013), o comportamento dos egressos mostra-se diferenciado, já que, entre filiados participantes após o PJB, foram encontrados $21 \%$, tendo $7 \%$ do geral interrompido sua participação ${ }^{18}$. Os dados analisados apontam para certa permanência no tempo de alguns dos efeitos verificados no comportamento dos jovens, mantendo-se relativamente estável a motivação para participação em partidos políticos, ainda que com forte tendência de decréscimo no interesse para candidatar-se a cargos políticos, fenômeno que é reforçado pela concorrência entre a participação política e a atuação acadêmica.

Os dados mostram que o PJB amplia a criticidade, o interesse e a participação na política, além de influenciar, em muitos casos, nos anseios de posicionamento social e na escolha de profissóes, conforme dados gerais da pesquisa ${ }^{19}$. Esses efeitos indicam que a iniciativa torna efetivo o que Castro (2009) aponta como outros caminhos para a reinvençáo da política, ao tornar os jovens concernidos com as

\footnotetext{
${ }^{18} \mathrm{O}$ instrumento de pesquisa não especificou a possível situação de desfiliação, apenas a interrupção da participação, mesmo tendo havido filiação posterior ao projeto.

${ }^{19}$ Aqui nos reportamos aos dados mais abrangentes da pesquisa náo abordados no recorte deste artigo.
} 
questôes da coletividade, aproximando o cidadão comum da política, o que pode, gradualmente, diminuir a centralização decisória nos políticos profissionais.

Uma análise qualitativa mais detalhada das respostas abertas dos egressos deste mesmo levantamento ${ }^{20}$ poderá ampliar esse conhecimento acerca dos efeitos cognitivos do PJB. Para efeito ilustrativo da análise desse recorte partidário, relata-se um trecho de uma resposta de egresso da edição de 2006, atualmente filiado a um partido político: "Minha participaçáo no PJB me tornou um jovem com mais coragem para assumir de vez a política e lutar para que ela seja exercida com qualidade, respeito, ética, democracia e participação popular” (J.M.O, masculino, 26 anos, residente em cidade do interior do Estado do Rio Grande do Sul).

$\mathrm{O}$ PJB pode ser considerado como uma iniciação dos participantes que nunca tiveram algum envolvimento com a política e uma etapa reforçadora da formação daqueles já participantes de movimentos sociais, de partidos políticos ou que possuem capital político familiar. Supóe-se que haja um efeito secundário, a ser medido extensivamente em estudos futuros, que seria a formaçáo de jovens lideranças alheias à lógica da eleição de familiares das oligarquias políticas, fenômeno verificado entre $40,7 \%$ dos deputados e deputadas federais eleitos, de 2002 a 2010, e que apresenta tendência de crescimento em todas as regiōes do país (MIGUEL, MARQUES e MACHADO, 2015). Identificados informalmente, já são conhecidos casos de três egressos que exercem cargos eletivos como vereador, sendo que um destes chegou à cadeira de Deputado Estadual.

Percebe-se que a participação no projeto, desde a aprovação dos jovens, gera uma ampla repercussão e reconhecimento desse cidadáo. Isso vai além do ambiente escolar, difundindo-se em veículos jornalísticos locais e também no meio político regional, inclusive nas câmaras de vereadores e assembleias legislativas. Foram identificadas sessóes públicas de homenagem direcionadas aos estudantes, anteriormente ou após a simulação parlamentar ${ }^{21}$. Essa valorização da ação política do jovem se caracteriza como uma descontinuidade do trajeto linear da história biográfica, oportunizando-se vivências e possibilidades subjetivas que reforçam o

\footnotetext{
${ }^{20}$ A análise qualitativa das respostas abertas será objeto de outro artigo.

${ }^{21}$ Esse fato foi observado durante a busca dos contatos dos egressos na internet para a aplicação da pesquisa. Notícia acerca do PJB como exemplo de difusão de informação gerada pela participação de jovens no PJB: http://www.araras.sp.leg.br/inscricao-para-parlamento-jovem-brasileiro-encerra-dia14/3666 Acessado em 25 fev. 2016.
} 
potencial emancipatório na relação entre jovens e adultos, conforme definido por Castro (2009).

É provável que experiências de educação e vivência como o PJB tenham o potencial, em grande medida, de reverter a lógica conjuntural de desconfiança quanto aos partidos políticos e do subsequente afastamento do público jovem dessa esfera, alterando assim o processo de desencantamento e "desintitucionalizaçáo" da ação política juvenil, conforme caracterizado por Augusto (2008). É importante destacar a ampla diferença quantitativa de participação e interesse de homens pela política em comparaçáo com as mulheres, que também se mostram motivadas positivamente à filiação e à militância partidária, mesmo que em proporção bem menor, o que reproduz uma característica cultural da sociedade brasileira.

Antonio Teixeira de Barros é Doutor em Sociologia. Professor e Pesquisador do Programa de Pós-Graduação do Centro de Formação Política da Câmara dos Deputados (CEFOR). E-mail: antonibarros@gmail.com.

Lúcio Meireles Martins é Mestrando em Ciência Política do Centro de Formação Política da Câmara de Deputados (CEFOR). Email: luciogoiano@hotmail.com.

\section{Referências}

ABRAMOVAY, Miriam; CASTRO, Mary Garcia (org.). Juventude, juventudes: o que une e o que separa. Brasília: Unesco, 2006.

ALMOND, Gabriel; VERBA, Sidney. The civic culture: political attitudes and democracy in five nations. Princeton: Princeton University Press, 1989.

AUGUSTO, Nuno Miguel. A juventude e a (s) política (s): Desinstitucionalização e individualização. Revista Crítica de Ciências Sociais, n. 81, 2008, p.155-177.

BAPTISTA, Érica Anita et al. Jovens eleitores e novas tecnologias: percepções da política e participação. Revista do Legislativo. Belo Horizonte, v. 5, n. 1, jan. 2013, p. 124-132.

BAUMAN, Zigmunt. A sociedade individualizada. Rio de Janeiro: Zahar, 2008.

BECK, Ulrich. A reinvenção da política: rumo a uma teoria da modernização reflexiva. In: GIDDENS, Anthony; LASH, Scott; BECK, Ulrich. Modernização reflexiva. São Paulo: EdUnesp, 1994, p. 11-87. 
BRASIL. Senado Federal. Diminui o número de filiados a partidos políticos. Disponível em: http://www12.senado.gov.br/jornal/edicoes/2014/09/30/diminui-o-numero-de-filiados-a-partidos Data: 30 de setembro de 2014. Acessado em 25 fev. 2016.

CASTRO, Lucia Rabello de. Juventude e socialização política: atualizando o debate. Psicologia: Teoria e Pesquisa, v. 25, n. 4, 2009, p. 479-487.

CASTRO, Lucia Rabello de. Participação política e juventude: do mal-estar à responsabilização frente ao destino comum. Revista Sociologia Política. Curitiba, v. 16, n. 30, 2008, p. 253-268.

COSSON, Rildo. Dois modelos de parlamento jovem: uma leitura de seu funcionamento como letramento político. Estudos Legislativos, v. 3, 2009, p. 34-45.

COSSON, Rildo. Escolas do legislativo: escolas de democracia. Brasília: Câmara dos Deputados, 2008.

DAYRELL, Juarez; MOREIRA, Maria Ignez Costa; STENGEL, Márcia (Org.). Juventudes contemporâneas: um mosaico de possibilidades. Belo Horizonte: Ed. PUC Minas, 2011.

DUBET, François. A formação dos indivíduos: a desinstitucionalização. Contemporaneidade $e$ Educação, v. 3, n. 3, 1998.

ELIAS, Norbert. A sociedade de indivíduos. Rio de Janeiro: Jorge Zahar, 1987.

FREIRE, Sara Andreia Moreira. Associativismo juvenil e diferentes formas de participação política: um estudo de caso. Dissertação (Mestrado em Sociologia). Universidade da Beira Interior. Covilhã, 2009. 249f.

GIDDENS, Anthony. As consequências da modernidade. $1^{\text {a }}$ ed. São Paulo: Editora UNESP, 1991.

GOHN, Maria da Glória. Os jovens e as praças dos indignados: territórios de cidadania. Revista Brasileira de Sociologia, v. 1, n. 2, p. 205-221, jul/dez 2013.

IBOPE. Após queda acentuada em 2013, Índice de Confiança Social se estabiliza. Matéria jornalística (sem citação de autor). $1^{\circ}$ de setembro de 2014. Disponível em: http://www.ibope.com.br/pt-br/noticias/Paginas/Ap\%C3\%B3s-queda-acentuada-em2013,Indice-de-Confianca-Social-se-estabiliza.aspx Acessado em 28 fev. 2015.

MALFITANO, Ana Paula Serrata. Juventudes e contemporaneidade: entre a autonomia e a tutela. Etnográfica, Lisboa, v. 15, n. 3, 2011, p. 523-542.

MAIR, Peter. Os Partidos Políticos e a Democracia. Análise Social, v. 37, n. 167, 2003, p. 277293.

MANIN, Bernard. A democracia do público reconsiderada. Novos Estudos - Cebrap, São Paulo, n. 97, 2013, p. 115-127.

MARTINS, Lúcio Meireles. Educomunicação para a democracia: o programa Plenarinho e o nível de letramento político infanto-juvenil. Monografia (especialização). Curso de Instituições e Processos Políticos do Legislativo, Câmara dos Deputados, Centro de Formação, Treinamento e Aperfeiçoamento $2012 . \quad$ (Cefor), 2016 . http://bd.camara.gov.br/bd/handle/bdcamara/10032?show=full. Acessado em 23 fev. 2016.

MENDONÇA, José Carlos. Partidos Políticos: da visão dos clássicos aos desafios da (pós?) modernidade. Em Tese, v. 4, n. 2, 2008, p. 67-83.

MIGUEL, Luis Felipe; MARQUES, Danusa; MACHADO, Carlos. Capital familiar e carreira política no Brasil: gênero, partido e região nas trajetórias para a Câmara dos Deputados. Dados, v. 58, n, 3. Rio de Janeiro, 2015, p. 721-47.

NASCIMENTO, Marcos Roberto. Parlamento Jovem, juventudes e participação política. In: MEDEIROS, Regina de P.; MARQUES, Maria E. (Orgs). Educação política da juventude: a experiência do Parlamento Jovem. Belo Horizonte: Editora PUC Minas, 2012, p. 305-325. 
NORRIS, Pipa. Young People \& Political Activism: From the Politics of Loyalties to the Politics of Choice? Report for the Council of Europe Symposium, 2003. Disponível em: http://www.pipanorris.com . Acessado em 15 fev. 2016.

OKADO, Lucas T. A. Juventude e participação polítca no Brasil: efeitos geracionais ou de ciclos de vida. Revista Espaço Acadêmico, na o XIII, n. 147, ago/2013, p. 37-50.

PEIRANO, Marisa. O dito e o feito. São Paulo: Relume-Dumará, 2011.

RIBEIRO, Eliane; LANES, Patrícia; CARRANO, Paulo. Diversidade de perfis caracteriza as juventudes brasileiras.

Ibase, 2006. http://www.ibase.br/userimages/ibasenet_dv30_indicadores.pdf Acessado em 20 fev. 2016.

RODRIGUES, Alan. O que os jovens pensam sobre a política. Revista IstoÉ. Edição 2336, 29 de agosto de 2014. Disponível em: http://www.istoe.com.br/reportagens/380009_O+QUE+OS+JOVENS+PENSAM+SOBRE+A+P OLITICA. Acessado em 20 fev. 16.

TELLES, Helcimara de S.; DIAS, Mariana. Condutas políticas, valores e voto dos eleitores jovens de Belo Horizonte. Revista do Legislativo. Belo Horizonte, n. 43, jan. 2010, p. 82-102.

TEIXEIRA COELHO, José. Cultura e cultura política dos jovens. Revista USP, n. 32, 1997, p. 156-165.

URBINATI, Nadia. Crise e metamorfoses da democracia. Revista Brasileira de Ciências Sociais, São Paulo, v. 28, n. 82, 2013, p. 5-16.

Texto recebido em 11 de março de 2016. Aprovado em 19 de julho de 2016. 